\title{
Non-Destructive Evaluation of Micro-Cracked SCC by Ultrasonic Waves
}

\author{
Irene Palomar ${ }^{1}$, Gonzalo Barluenga ${ }^{1}$, Hugo Varela ${ }^{1}$, Javier Puentes ${ }^{2}$ and Ángel \\ Rodríguez $^{3}$ \\ ${ }^{1}$ Department of Architecture, University of Alcala, Madrid, Spain, irene.palomar@uah.es; \\ gonzalo.barluenga@uah.es; hugo.varela@edu.uah.es \\ ${ }^{2}$ Institute of Construction Sciences Eduardo Torroja, CSIC, Spain, javier.puentes@ietcc.csic.es \\ ${ }^{3}$ Systems Engineering and Automation Dept., University Carlos III of Madrid, Spain, \\ angrodri@ing.uc3m.es
}

\begin{abstract}
Self-Compacting Concrete (SCC) is an effective, reliable and safer technology to cast-inplace concrete structures. However, the large amount of paste required to achieve its high flowability may increase drying shrinkage at early age, due to the undesirable effects of curing conditions, producing micro-cracking and damaging concrete members. When this happens, an evaluation of the hardened SCC is necessary and Non-destructive testing techniques (NDT) can be suitable. Among NDT, Ultrasonic pulses (US) have showed to be very useful due to its portability, easiness of application and sensitivity to changes in material microstructure, porosity and presence of defects. In order to evaluate the applicability of ultrasonic (US) waves to better understand the relations among composition, microstructure, properties, curing conditions and micro-cracking, an experimental program using transmission P- and S- waves was carried out on SCC with limestone filler (LF), microsilica (MS) and nanosilica (NS), set and hardened under different curing conditions: 10,20 and $30^{\circ} \mathrm{C}$ and 40 and 80 $\%$ relative humidity. Free shrinkage and double displacement restrained slabs were tested and cracking potential due to Early Age Shrinkage was assessed. Ultrasonic transmission time and wave amplitude of the raw US signal were measured and Ultrasonic pulse velocity (UPV) and attenuation coefficient were calculated. In addition, some physical and mechanical properties of cracked and un-cracked samples were measured. The aim of this study was to compare US parameters to hardened properties of cracked and un-cracked SCC. Correlations for SCC micro-cracking based on US parameters were identified, demonstrating the potential of using transmission US P-and $S$-waves as an evaluation technique for micro-damaged SCC.
\end{abstract}

Keywords: Ultrasonic, P and S Waves, Micro-Cracking, SCC, Hardened Properties.

\section{Introduction}

Self-Compacting Concrete (SCC) is designed to improve cast-in-place structures by increasing paste phase and enhancing fresh rheology. However, larger paste volume makes SCC more sensitive to curing conditions, increasing early age (EA) drying shrinkage and micro-cracking potential (Puentes et al., 2014). SCC usually incorporates supplementary cementitious materials (SCM) in its composition. The type and amount of SCM used has been identified to also affect cracking potential damage jointly with curing conditions on SCC with limestone filler, microsilica and nanosilica (Barluenga et al., 2018). When EA cracking occurs, an evaluation of the hardened properties of SCC is necessary. Among the Non-destructive testing techniques (NDT) available, radar, electrical resistivity, capacitance measurements and ultrasound have been described to be suitable for estimating material properties (Garnier et al., 2013). Ultrasonic 
pulses (US) is often preferred due to its portability, easiness of application and sensitivity to changes in material microstructure, porosity and defect detection (Selleck et al., 1998; Aggelis, 2013; Barluenga et al., 2015; Palomar et al., 2017). US parameters such as ultrasonic transmission times and wave amplitude of the raw US signal propagated through the material can be used to evaluate the relations among composition, microstructure, properties, curing conditions and micro-cracking (Yim et al., 2012; Shiotani et al., 2009). The most commonly used US wave type is compressive or P-wave, although there are transducers commercially available that combine $\mathrm{P}$ - and $\mathrm{S}$-waves (shear pulses). Thus, the wave velocity propagation (UPV), the wave attenuation coefficient (AT) and Young modulus, Shear modulus and Poisson's coefficient ratio can be calculated (Palomar et al., 2017). The combination of US parameters considering both UPV and AT can be used for concrete micro-cracking assessment (Shiotani et al., 2009).

The aim of this study was to compare US parameters to hardened properties of cracked and un-cracked SCC with limestone filler (LF), microsilica (MS) and nanosilica (NS). An experimental program using transmission P- and S- waves was carried out on SCC set and hardened under different curing conditions. The applicability of ultrasonic (US) waves to better understand the relations among composition, microstructure, properties, curing conditions and micro-cracking was evaluated.

\section{Experimental Program}
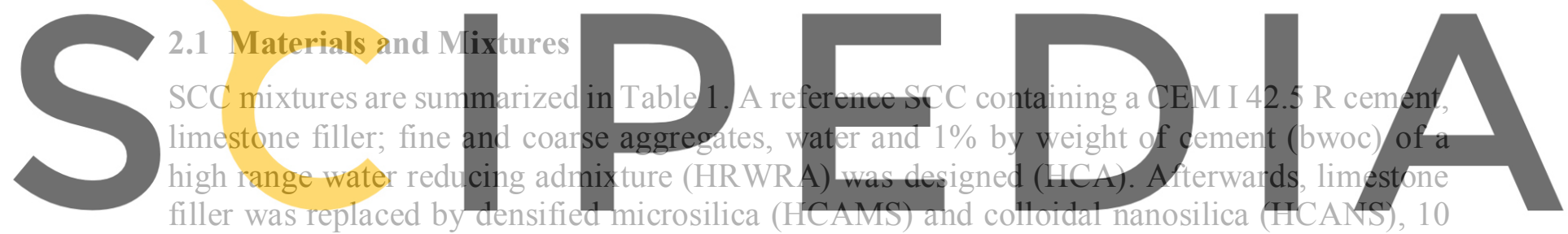
and 5\% bwoc respectively (see Barluenga et al., 2018 for further descriptions)

Register for free at https//www.scipedia.com to download the version without the watermark 2.2 Experimental Methods and Prelimimary Results

\subsubsection{Early age cracking potential in different curing conditions}

Early age (EA) cracking potential was measured using a double restrained slab test subjected to 10,20 and $30{ }^{\circ} \mathrm{C}$ curing temperatures and 40 and $80 \%$ relative humidity (RH) during the first $24 \mathrm{~h}$. The test setup consisted of $400 \times 300 \times 45 \mathrm{~mm}$ slabs, with double displacement restricted by internal plugs attached to the mold, in order to maximize EA cracking potential (Barluenga et al., 2018). The slabs were demolded at $24 \mathrm{~h}$ and stored in laboratory conditions until crack measurement at 7 days. The cracked area $\left(A_{c}\right)$ summarized in Table 2 was calculated measuring cracks length (L) and width (W) (Puentes et al., 2014). The results of the SCC mixes with filler (HCA) showed high $\mathrm{A}_{\mathrm{c}}$. It can also be observed that the L and $\mathrm{W}$ for HCA were higher, especially at $20^{\circ} \mathrm{C}$ and $40 \%$ RH. SCC with Microsilica (HCAMS) reduced significantly EA cracking, except for hot-dry conditions. In the case of SCC with nanosilica (HCANS) $\mathrm{A}_{\mathrm{c}}$ was slightly lower, although the cracks were narrower than HCA and HCAMS. In general, silica based additions at hot-dry conditions showed a high EA cracking risk, whereas it was minimized 
in hot-wet conditions. The increase of hydration speed and microstructure formation in hot-dry curing conditions may explain this effect on EA cracking (Barluenga et al., 2018).

Table 1. SCC Compositions $\left(\mathrm{kg} / \mathrm{m}^{3}\right)$.

\begin{tabular}{lccc}
\hline & HCA & HCAMS & HCANS \\
\hline Cement & 350 & 350 & 350 \\
Limestone Filler & 350 & 315 & 332.5 \\
Gravel (4-20 mm) & 790 & 790 & 790 \\
Sand (0-4 mm) & 679 & 679 & 679 \\
Microsilica & - & 35 & - \\
Nanosilica & - & - & 79.5 \\
Water* & 179 & 179 & 117 \\
HRWRA & 3.5 & 3.5 & 3.5 \\
w/c** & 0.6 & 0.6 & 0.6 \\
W/b** & 0.3 & 0.3 & 0.3 \\
\hline
\end{tabular}

* Liquid water added.

** The amount of water included in the components (sand humidity (4.3\%), SP and NS) was also considered.

Table 2. Early age cracking parameters. Physical and mechanical properties at hardened state.

\begin{tabular}{|c|c|c|c|c|c|c|c|}
\hline & $\underset{\mathrm{mm}^{2} / \mathrm{m}^{2}}{\mathbf{A c}_{\mathbf{c}}}$ & $\begin{array}{c}\mathbf{L}_{\max } \\
\mathrm{mm}\end{array}$ & $\begin{array}{l}\mathbf{W}_{\mathrm{m}} \\
\mathrm{mm}\end{array}$ & $\begin{array}{c}\mathbf{A E R} * \\
10^{3} \mathrm{ml} / \mathrm{s} \mathrm{mm}^{2}\end{array}$ & $\begin{array}{c}\text { WAR * } \\
10^{6} \mathrm{ml} / \mathrm{s} \mathrm{mm}^{2}\end{array}$ & $\begin{array}{c}\mathbf{P o}^{* *} \\
\% \\
\end{array}$ & $\begin{array}{l}\mathrm{CS}^{* *} \\
\mathrm{MPa}\end{array}$ \\
\hline HCA & 539 & 66 & 0.17 & 0.48 & 0.93 & 2.34 & 34 \\
\hline $10-40$ & 353 & 70 & & 0.63 & & 2.55 & 35 \\
\hline $10-80$ & 448 & 90 & 0.1 & 0.27 & 1.0 & 11 & 30 \\
\hline $20-40$ & 2139 & 145 & 0.6 & 0.45 & & 85 & 35 \\
\hline $20-80$ & 0 & 0 & $\gamma$ & 0.73 & & 21 & 3 \\
\hline $30-40$ & 42 & 25 & 0.05 & & & - & \\
\hline $30-80$ & 253 & 65 & 0.06 & 0.13 & 0.50 & 0.97 & 37 \\
\hline $\begin{array}{l}\text { HCAMS } \\
\text { or fteq }\end{array}$ & $\begin{array}{c}122 \\
\text { https, }\end{array}$ & $\frac{17}{\mathrm{~W}_{2} \mathrm{SCl}^{-}}$ & 0.05 & dowkiloa & 1.02 & $\begin{array}{l}1.88 \\
\text { n.watk }\end{array}$ & $\begin{array}{c}33 \\
\text { they }\end{array}$ \\
\hline $10-80$ & 0 & 0 & 0 & 0.12 & 1.52 & 1.28 & 36 \\
\hline $20-40$ & 0 & 0 & 0 & 0.09 & 0.67 & 2.22 & 32 \\
\hline $20-80$ & 0 & 0 & 0 & 0.17 & 0.83 & 2.33 & 37 \\
\hline $30-40$ & 641 & 75 & 0.21 & 0.47 & 1.37 & 2.06 & 29 \\
\hline $30-80$ & 0 & 0 & 0 & 0.07 & 0.67 & 0.92 & 30 \\
\hline HCANS & 327 & 59 & 0.06 & 0.22 & 1.05 & 2.29 & 36 \\
\hline $10-40$ & 166 & 70 & 0.06 & 0.16 & 2.18 & 1.98 & 42 \\
\hline $10-80$ & 231 & 50 & 0.05 & 0.31 & 1.09 & 2.58 & 37 \\
\hline $20-40$ & 391 & 140 & 0.12 & 0.10 & 0.51 & 1.43 & 34 \\
\hline $20-80$ & 592 & 55 & 0.05 & 0.17 & 0.94 & 2.21 & 36 \\
\hline $30-40$ & 584 & 40 & 0.06 & 0.25 & 0.70 & 4.64 & 33 \\
\hline $30-80$ & 0 & 0 & 0 & 0.32 & 0.87 & 0.89 & 36 \\
\hline
\end{tabular}

\subsubsection{NDT assessment by ultrasonic pulse propagation}

Ultrasonic pulses (US) were applied on hardened samples of cracked and un-cracked SCC samples with dimensions of $400 \times 300 \times 45 \mathrm{~mm}$ and $60 \times 50 \times 100 \mathrm{~mm}$, respectively. P- and S- 
waves $250 \mathrm{kHz}$ transducers were used. The amplitude (V) in time domain ( $\mu \mathrm{s})$ of the P- and Swave raw signal through SCC samples were obtained. P-wave (Pw) and $\mathrm{S}$-wave (Sw) pulse velocity were identified using the Hilbert transform algorithm (Birgül, 2009). In addition, attenuation coefficient $\left(\mathrm{AT}_{250}\right)$ was calculated (Palomar et al., 2017), where the higher $\mathrm{AT}_{250}$, the lower the US energy absorbed by the SCC sample.

\subsubsection{SCC hardened properties}

Table 2 also summarizes several hardened physical and mechanical properties measured on 400 x 300 x $45 \mathrm{~mm}$ cracked slabs or 100 x 100 x $100 \mathrm{~mm}$ un-cracked samples. Air and water permeability were measured on cracked SCC slabs with a Figg's method based apparatus (Porosiscope ${ }^{\mathrm{TM}}$ ). The measured time for air or water to permeate through the concrete was used to estimate Air Exclusion Rating (AER) and Water Absorption Rate (WAR), respectively (Barluenga et al., 2017). Open porosity accessible to water $\left(\mathrm{P}_{\mathrm{O}}\right)$ and compressive strength (CS) were measured on cubic un-cracked samples at 28 days. HCA showed higher air permeability than SCC with silica based additions, while water permeability values were similar for all SCC compositions. Regarding curing conditions, HCA and HCANS samples showed large AER values even when cracks were not observed on the slabs. In contrast, the most damaged HCAMS slab presented the highest AER value. WAR was larger for HCA and HCAMS slabs without visible damage. SCC with nanosilica (HCANS) produced large values of WAR at colddry conditions despite its higher CS. Some correlations among the composition parameters, hardened properties and curing conditions have been described in a previous work (Barlueng et al., 2018). Regarding SCC compositions, HCAMS reduced increased compressive strength. In general, independently to the SCC domposition, and increased C environment on HCMS and HCANS produced

higher CS
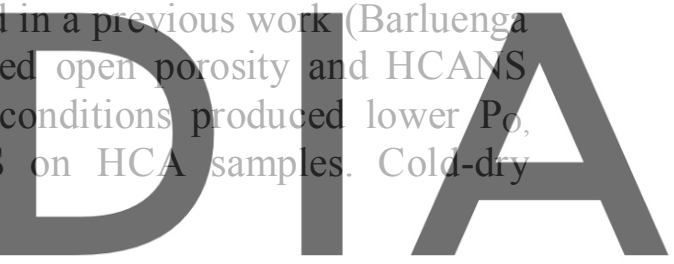

Table 3. P- and S-wave velocity and attenuation coefficient of US signal for SCC un-cracked samples.

Register for free at https//www.scipedia, com to downdoad the verrsion without the watermark

\begin{tabular}{lccc} 
& $\mathrm{m} / \mathrm{s}$ & $\mathrm{m} / \mathrm{s}$ & $\mathrm{dB} / \mathrm{mm}$ \\
\hline HCA & 3938 & 2472 & 0.36 \\
HCAMS & 3926 & 2342 & 0.53 \\
HCANS & 3684 & 2201 & 0.52 \\
\hline
\end{tabular}

\section{Experimental Results and Discussion}

\subsection{Ultrasonic Characterization of Un-Cracked SCC Samples}

Table 3 summarizes the experimental results of $\mathrm{P}$ - and $\mathrm{S}$-wave propagation velocities ( $\mathrm{Pw}$ and $\mathrm{Sw})$ and attenuation coefficient $\left(\mathrm{AT}_{250}\right)$ of un-cracked SCC samples. $\mathrm{Pw}$ and $\mathrm{AT}_{250}$ presented lower variability related to SCC compositions. In contrast, Sw was sensitive to SCC composition: the smaller the particle size, the slower S-wave propagation velocity. Figure 1 plots the experimental results of $\mathrm{Pw}$ and $\mathrm{Sw}$ and $\mathrm{AT}_{250}$ of un-cracked SCC samples in different curing conditions. Pw and AT250 presented a high variability, although they showed different trends, while Sw did not depend on curing conditions. 


\subsection{Ultrasonic Evaluation of Cracked SCC Samples}

Figure 2 and 3 plot the experimental results of $\mathrm{Pw}$ and $\mathrm{Sw}$ and $\mathrm{AT}_{250}$ of cracked SCC samples.
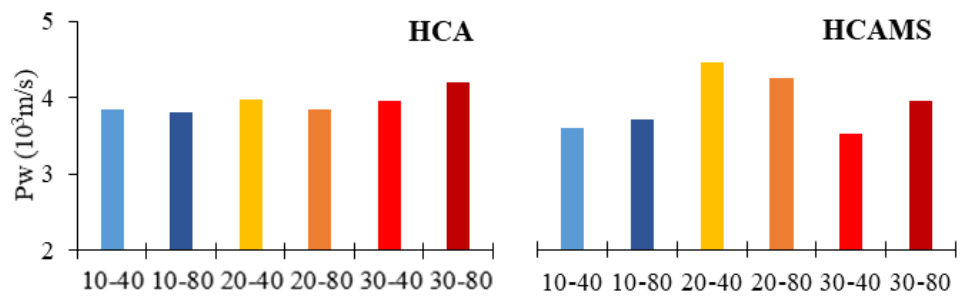

HCANS
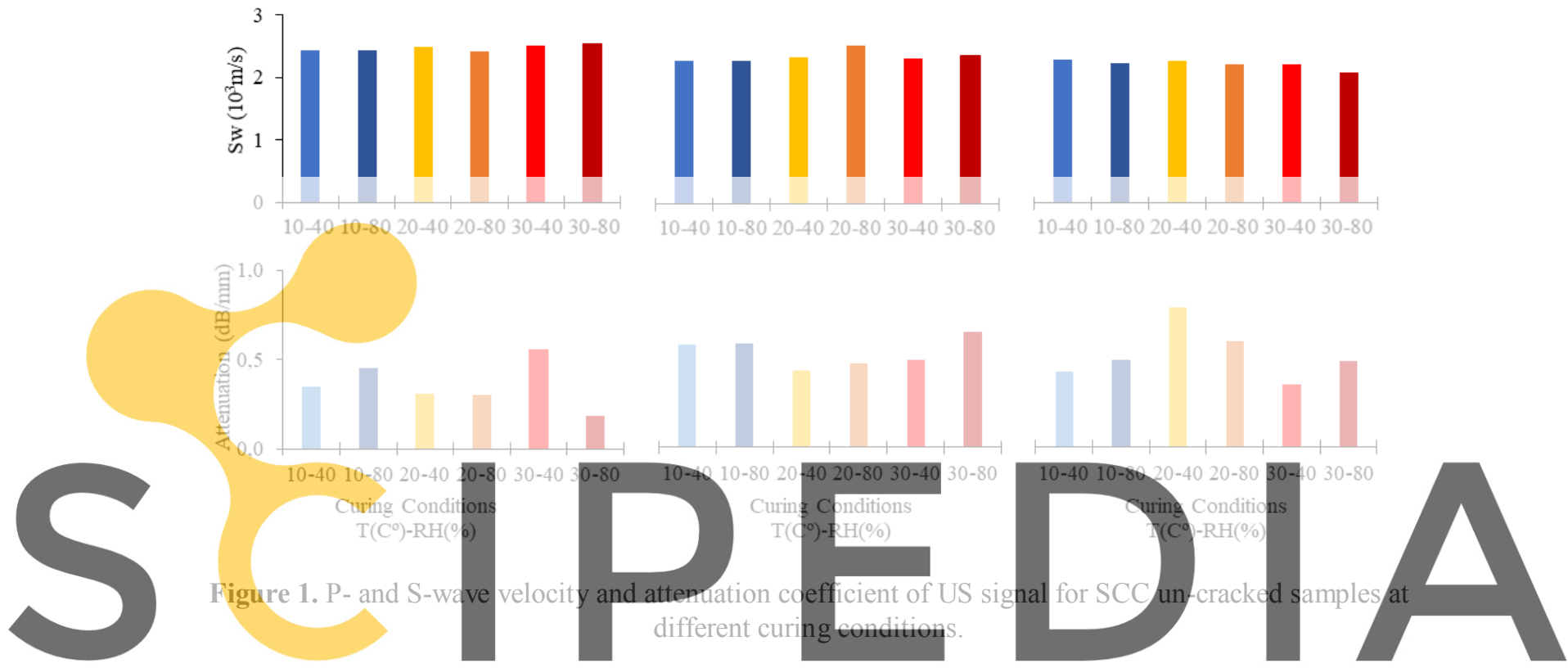

Register for free at https//www.scipedia.com to download the version without the watermark
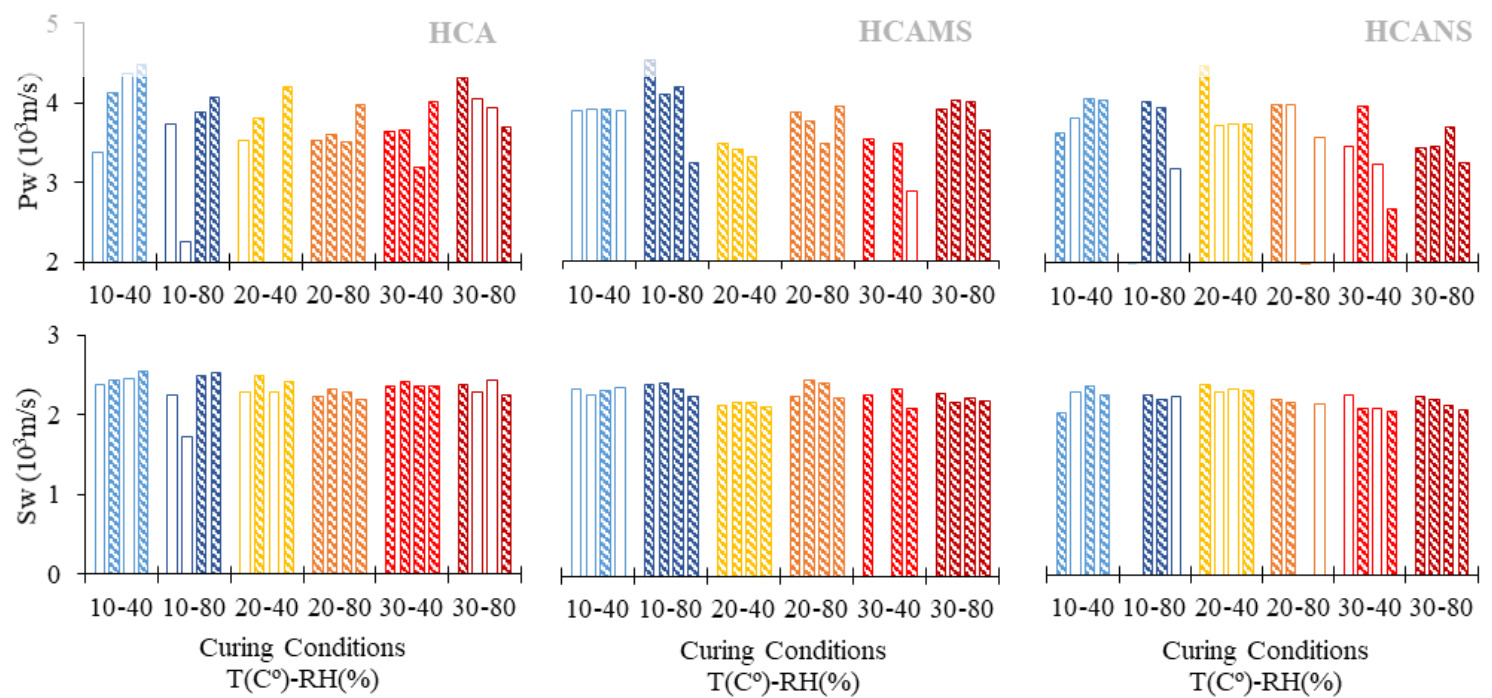

Figure 2. P- and S-wave velocity of US signal for SCC cracked samples at different curing conditions. 
US propagation was measured on damaged slabs with visible (VC) and non-visible cracks (NVC). Regarding US velocities, Pw scatter was slightly higher in cracked samples than in uncracked samples, although cracked values were lower than un-cracked. Pw on NVC was around $230 \mathrm{~m} / \mathrm{s}$ faster than VC. Sw showed very low variability on cracked samples despite the effect of composition, curing conditions and NVC or VC. In addition, some damaged samples showed similar $\mathrm{Pw}$ and $\mathrm{Sw}$ values, with differences smaller than $1000 \mathrm{~m} / \mathrm{s}$. These values do not correspond to undamaged SCC and cannot be used to calculate mechanical properties of damaged slabs, as elastic modulus or Poisson Coefficient (Barluenga et al., 2018).

A large dispersion of attenuation was recorded for cracked samples (Figure 3) and $\mathrm{AT}_{250}$ was higher for $\mathrm{VC}$ than $\mathrm{NVC}$. The highest $\mathrm{AT}_{250}$ values (closely $1.00 \mathrm{~dB} / \mathrm{mm}$ ) corresponded to the widest cracks measured (HCA-1080 and 2040 and HCAMS-3040). Thus, cracks decreased the amplitude of the wave in damaged areas due to scattering and diffraction effects (Yim et al., 2012). These results points out the sensitivity of $\mathrm{AT}_{250}$ to concentrated damage as visible cracks. However, some cracks produced by EA shrinkage of displacement restrained SCC members can progress from inside of the sample (Serpukhov et al., 2010), producing $A_{2} T_{25}$ values with little differences between $\mathrm{VC}$ and NVC areas. Accordingly, $\mathrm{AT}_{250}$ can detect both VC and NVC.
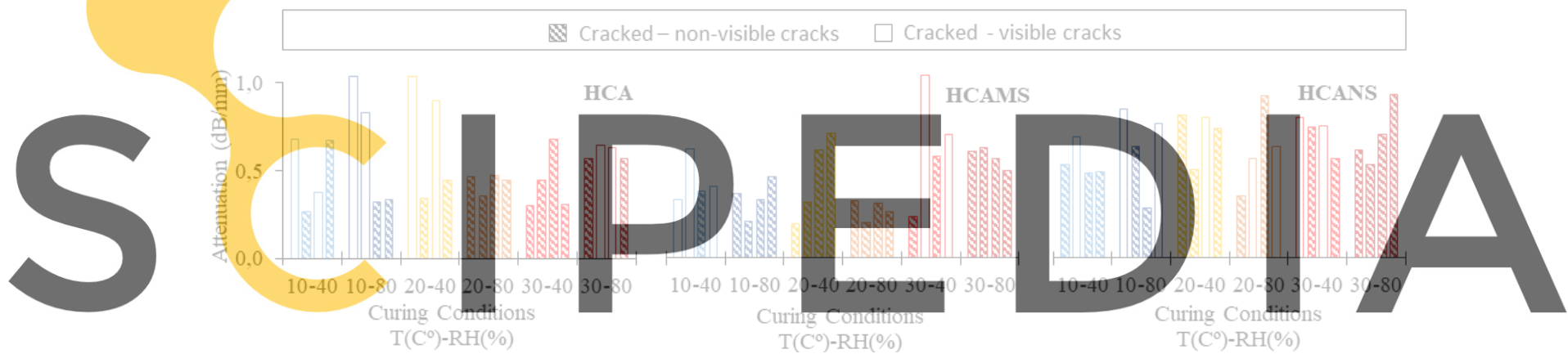

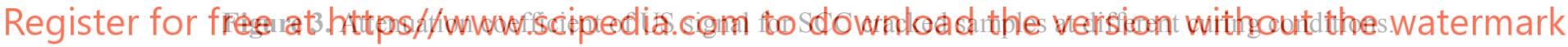

\subsection{Damage Evaluation of SCC Using NDT}

An evaluation of damage and cracking potential by US analysis was carried out and is plotted in Figures 4 and 5, respectively. Regarding damage and US parameters, in general velocities of cracked samples were slower than on un-cracked samples (Selleck et al., 1998), except HCA and HCAMS cured at $10^{\circ} \mathrm{C}$. On the other hand, two behaviors were identified in $\mathrm{AT}_{250}$ : 1) HCA and HCANS; values of un-cracked samples were lower than cracked ones; 2) HCAMS $\mathrm{AT}_{250}$ values were higher for un-cracked than for cracked samples. These differences can be explained considering the effect of SCC composition on cracking potential. HCA and HCANS showed larger cracking potential, whereas HCAMS cracking potential was remarkably lower. There were two exceptions to this trends: HCAMS 3040 (visible damage) and HCANS-2040 (red labeled in the graph). This last case showed long and wide cracks and low AER and WAR, meaning concentrated damages that can explain its exceptionality.

As a predictive tool for EA cracking potential of SCC, cracked area $\left(\mathrm{A}_{c}\right)$ can be compared to the ratio between $\mathrm{Pw}$ and $\mathrm{Sw}(\mathrm{Pw} / \mathrm{Sw})$ of un-cracked samples (Figure 5). The results showed an inverse relationship between $\mathrm{Pw} / \mathrm{Sw}$ and $\mathrm{A}_{\mathrm{c}}$ until a constant value of 1.60 or 1.80 , which 
depended on sample composition. A ratio of 1.80 means a Poisson's ratio (v) around 0.28: the larger the ratio the lower the compressibility. Therefore, if the un-cracked sample reaches a certain $\mathrm{Pw} / \mathrm{Sw}$ or compressibility, EA cracking potential will be minimized (HCAMS and HCANS). In the case of HCA, Pw/Sw showed littele cracking potential variability.

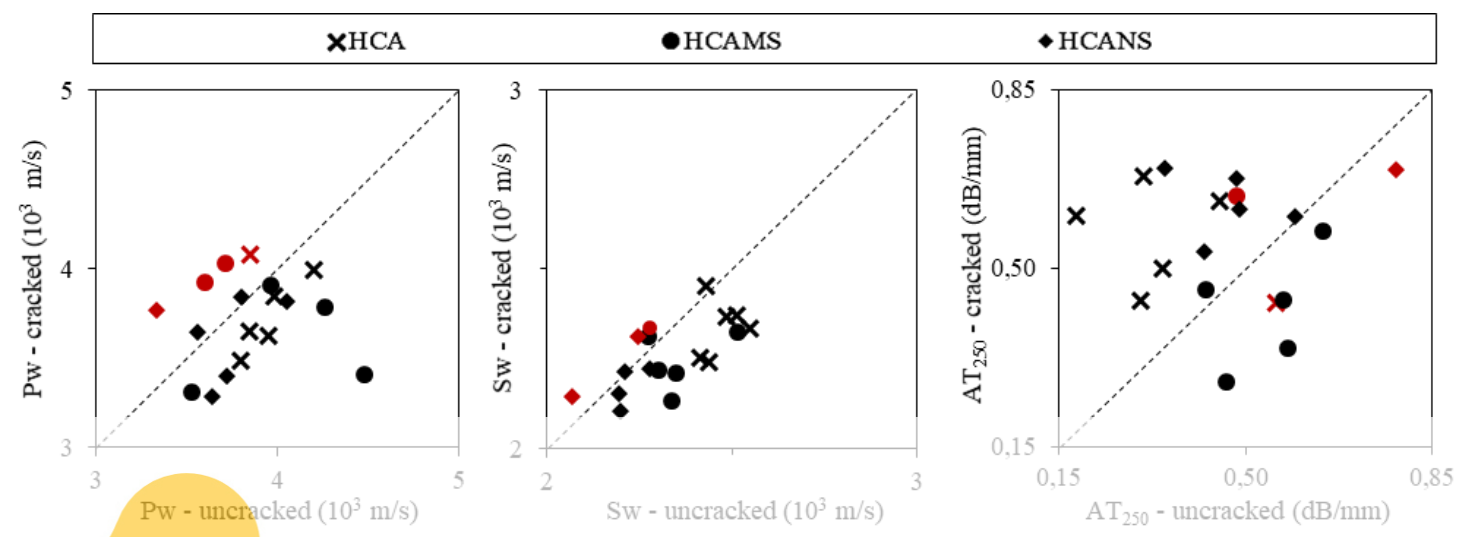

Figure 4. Ultrasonic pulse velocity and attenuation coefficient: un-cracked vs cracked values.
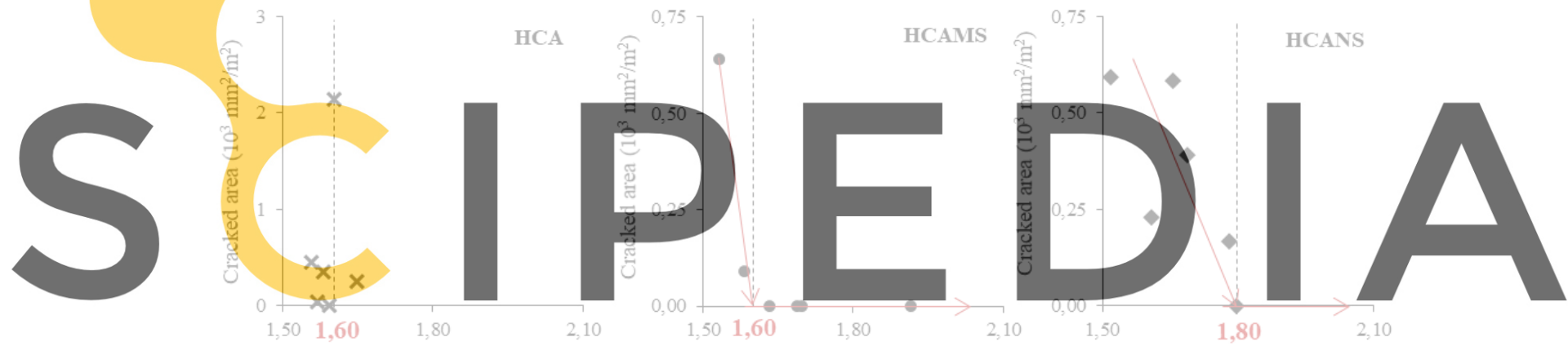

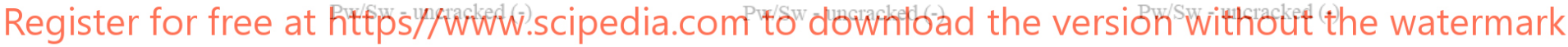

Figure 5. P- and S-wave velocity ratio $(\mathrm{Pw} / \mathrm{Sw})$ for un-cracked samples vs EA cracking parameters $\left(\mathrm{A}_{c}\right)$.

\section{Conclusions}

The applicability of ultrasonic (US) waves to better understand the relations among composition, microstructure, properties, curing conditions and early age cracking potential of SCC with limestone filler (LF), microsilica (MS) and nanosilica (NS) was assessed. The influence of composition, curing conditions and micro-damage on US parameters (P- and Swave velocities and signal attenuation) were analyzed. The main conclusions were:

- Changes in SCC compositions and curing conditions modified early age (EA) cracking potential and hardened properties.

- SCC compositions and curing conditions had a significant effect on US velocity propagation and attenuation coefficient in un-cracked and cracked samples, although the effect on US parameters it is not linear.

- US parameters were identified as key parameters to assess the micro-damage or the EA cracking potential of SCC.

- US velocities of un-cracked samples were higher than those of cracked samples. The 
attenuation coefficient of un-cracked SCC was lower than the damaged samples, either when the cracks were externally visible and when they were internal and non-visible.

- EA cracking potential was estimated for samples set and hardened under same curing conditions, using $\mathrm{P}$ - and $\mathrm{S}$-wave velocity ratio $(\mathrm{Pw} / \mathrm{Sw})$ of un-cracked samples.

\section{Acknowledgements}

Financial support was provided by the Spanish Ministry of Economy \& Competitiveness (NanoCompaC, BIA2016-77911-R) and UAH (postdoctoral fellowship - Ayuda Postdoctoral/Modalidad A/2017). Some of the components were supplied by BASF Spain S.L, Omya Clariana S.L, and Portland Cement Vaderrivas.

\section{ORCID}

Irene Palomar: https://orcid.org/0000-0003-2743-3618

Gonzalo Barluenga: https://orcid.org/0000-0002-2996-3412

Hugo Varela: https://orcid.org/0000-0001-8094-6071

Javier Puentes: https://orcid.org/0000-0001-8748-7664

Ángel Rodríguez: http://orcid.org/0000-0002-6897-2194

\section{References}

Aggelis, D.G. (2013). Wave propagation through engineering materials; assessment and monitoring of structures through non-destructive techniques. Materials and Structures, 46, 519-532. doi: 10.1617/s11527-013-0020-x

Barluenga, G., Guardia, C. and Puentes, J. (2018). Effect of curing temperature and relative humidity on early age and hardened properties of SCC. Construction and Building Materials, 167, 235-242. doi: 10.1016/j.conbuildmat.

Barluenga, G., Guardia, durability of SCC. In $P$. and Components (RILI

Barluenga, G., Palomar, additions. Construction
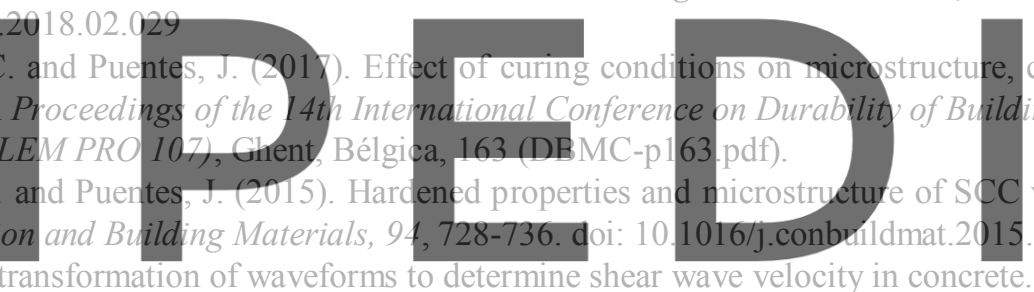

Birgül, R. (2009). Hilbert transformation of waveforms to determine shear wave velocity in concrete. Cement and Concrete Research, 39(8), 696-700. doi: 10.1016/j.cemconres.2009.05.003

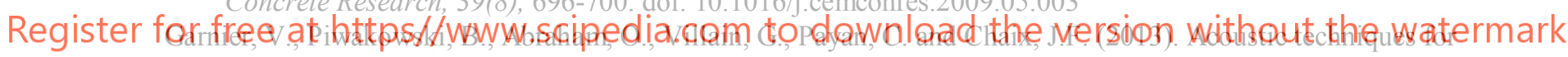
concrete evaluation: Improvements, comparisons and consistency. Construction and Building Materials, 43, 598-613. doi: 10.1016/j.conbuildmat.2013.01.035

Palomar, I. and Barluenga, G. (2017). Assessment of lime-cement mortar microstructure and properties by P-and S- ultrasonic waves. Construction and Building Materials, 139, 334-341. doi: 10.1016/j.conbuildmat.2017.02.083

Puentes, J., Barluenga, G. and Palomar, I. (2014). Effects of nano-components on early age cracking of selfcompacting concretes. Construction and Building Materials, 73, 89-96. doi: 10.1016/j.conbuildmat.2014.09.061

Selleck, S.F., Landis, E.N., Peterson, M.L., Shah, S.P. and Achenbach, J.D. (1998). Ultrasonic Investigation of Concrete with Distributed Damage. ACI Materials Journal, 95-M4, 27-36.

Serpukhov, I. and Mechtcherine, V. (2015). Early-age shrinkage of ordinary concrete and strain-hardening cementbased composite (SHCC) in conditions of hot-weather casting. In Proceedings of the 10th International Conference on Mechanics and Physics of Creep. Shrinkage, and Durability of Concrete and Concrete Structures, Vienna, Austria, 1504-1513. doi: 10.1061/9780784479346.176

Shiotani, T. and Aggelis, D.G. (2009). Wave propagation in cementitious material containing artificial distributed damage. Materials and Structures, 42(3), 377-384. doi: 10.1617/s11527-008-9388-4

Yim, H.J., Kwak H.G. and Kim J.H. (2012). Wave attenuation measurement technique for nondestructive evaluation of concrete. Nondestructive Testing and Evaluation, 27(1), 81-94. doi: $10.1080 / 10589759.2011 .606319$ 